\title{
Decontamination Technology of Contaminated Water with Flocculating and Settling Technology*
}

\author{
Masanori ARITOMI**, Toshihiro ADACHI**, Shigeki HOSOBUCHI*** \\ and Noriyuki WATANABE** \\ ** Research Laboratory for Nuclear Reactors, Tokyo Institute of Technology \\ 2-12-1, N1-13, Ohokayama, Meguro-ku, Tokyo, 152-8550 Japan \\ E-mail: maritomi@nr.titech.ac.jp \\ *** Specified Non-Profit Organization Saiseisha
}

3-10-11, Shirahata, Minami-ku, Saitama-City, Saitama, 336-0022 Japan

\begin{abstract}
In the joint research and development of treatment systems of cooling water for cutting asphalt pavement surface with our authors' group, the liquid-solid separation technology by flocculating and settling technology, and the flocculants for the use of systems were developed. In this paper, the developed flocculating and settling technology and the flocculants are discussed first. Next, the demonstration tests of decontamination technology on the contaminated water in swimming pools in an elementary school located at Motomiya City, Fukushima Prefecture had been conducted by use of the stationary purification system of contaminated water and the flocculants compounding with or without iron ferrocianide developed by the preliminary test. It was clarified from the results that ionized cesium (Cs) rarely exists in the stagnant water in pools, ponds, lakes and so on at the time when nine months have passed since Fukushima Dai-ichi nuclear power plant accidents. Further, it is necessary to use the flocculants compounding iron ferrocianide in the case where ionized Cs exists in water. From the above-mentioned results, the following problems were pointed out: One problem was cyanide dissolution in the purified water and the other one was the dissolution from the dehydration sludge. Finally, the high-performance mobile purification units of contaminated water which is capable for carrying with trucks have been developed, and the demonstration test was performed in Minami-soma City, Fukushima Prefecture to purify the contaminated water in a pond and generated by the high-pressure water washing in a Public Hall. From the test results, it was made clear that the dehydration sludge separated by liquid-solid settling of the contaminated water of around $1,000 \mathrm{~Bq} / \ell$ became a high radiation dose of about $185,000 \mathrm{~Bq} / \ell$.
\end{abstract}

Key words: Decontamination Technology, Radioactively Contaminated Water, Flocculating and Settling Technology, Flocculants, Purification Units of Contaminated Water, Fukushima Dai-ichi Nuclear Power Plant Accidents

\section{Introduction}

Aritomi jointly worked with Specified Non-Profit Organization (NPO) Saiseisha for the development of flocculating and settling technology and flocculants (so called "Ion reaction") and initially developed a mobile treatment system of cooling water for cutting asphalt pavement surface ${ }^{(1)}$ which is able to be transported by a $3 t$ truck. Since then, the development of a stationary purification system of contaminated water was initiated in order to make expansion of the processing capacity. At the time when almost of all the

Received 19 July, 2012 (No. 12-0298)

DOI: 10.1299/jpes.6.412]

Copyright $(\subset) 2012$ by JSME 
construction of the system was completed, Fukushima Dai-ichi Nuclear Power Plant (NPP) accidents occurred.

The sea water as the coolant had been injected into the reactor cores and the spent fuel cooling pools after the Fukushima Dai-ichi NPP accidents. It had been assumed that the salt concentration of the injected sea water was gradually going to the higher level by its evaporation. Therefore, Aritomi insisted on the exchange from sea water to fresh water as soon as possible in order to prevent the corrosion of the reactor construction materials and deterioration of the heat-transfer performance. Then, the development of decontamination technology of sea water coolant contaminated with radioactive materials was initiated and the chemical system study group of the Research laboratory for Nuclear Reactors at the Tokyo Institute of Technology found out that iron ferrocyanide could be applied to the adsorption of ionized $\mathrm{Cs}$ in the scientific literature ${ }^{(2)}$. Iron ferrocyanide is the major content of Prussian blue which had been used as pigments since the Edo period of time in Japan, and it had been found that it can be available with cheap price. Iron ferrocyanide was put in the contaminated water simulated by non-radioactive $\mathrm{Cs}$, and this mixture was agitated and the suspended solids were separated by the filter papers in the beaker. It has become apparent from the results that the decontamination factor of $1 / 10,000$ could be realized ${ }^{(3)}$.

By combining two results mentioned above, the flocculants were firstly developed for the purpose to decontaminate the contaminated paddle of water and streams to supply as agricultural water, or for the purpose to purify contaminated water generated from decontamination of the contaminated residential buildings, roads, rubbles, soils and so on and to discharge safely into sewages. Then, the mobile purification unit which remodeled from the mobile treatment unit of water generated in cutting asphalt pavement surface was manufactured. In addition, the stationary purification system of contaminated water was also done, which can be transported by trucks after disassembled and be assembled on site. The decontamination technology was finally established.

In this paper, the established flocculating and settling technology and flocculants are presented. Next, the characteristics of Cs in contaminated pool water as a puddle of water in nine months after the NPP accidents and its decontamination technology are discussed. Further, the mobile purification unit of contaminated water, which is a newly developed and the performance ability was improved, is introduced. Finally, both the problems to be taken at the time when eliminating the ionized Cs by use of iron ferrocianide and the development of their countermeasure technologies are discussed.

\section{Development of flocculating and settling method and flocculants}

Aritomi and the NPO Saiseisha revealed from a chemical analysis of the turbid water in cutting asphalt pavement surface that its water contains not only high in suspended solids but also high in hydrogen-ion concentration $(\mathrm{pH})$ level and in the volume of normal-hexane extracts, and that the carcinogenic polycyclic aromatic hydrocarbon (PAH) is contained in it. Therefore, the treatment technology to prevent discharging the turbid water into sewages was initially developed. Preliminary tests by use of beakers were repeatedly carried out, then the flocculants to make flocculate and set suspended solids and to make them liquid-solid separating were developed. Finally, the flocculating and settling technology was established through these processes, which can control $\mathrm{pH}$, shift substances of normal-hexane extracts and PAH from the turbid water to the aggregation and sedimentation.

The flocculant is an inorganic powder which consists primarily of alminium-sulphate, silica sand, calcium oxide, activated carbon and others. In this paper, "flocculant" means the powder which has the flocculating and precipitating functions as put in water mixed with suspended solid. Next, the treatment unit of turbid water generated in cutting asphalt 
pavement surface was manufactured. The unit can send the aggregation and sedimentation substances to an efficient liquid-solid separator with such a pump which does not destruct them and can be carried by a $3 \mathrm{t}$ truck.

A Schematic diagram of the developed treatment unit for turbid water generated by cutting asphalt pavement surface is shown in Fig.1. The turbid water was withdrawn by a vacuum suction, cutting machine and a washing machine and then pumped up to the raw water stir tank. The stir tank is installed with a screening box having $1 \mathrm{~mm}$ screen and suspended solids larger than $1 \mathrm{~mm}$ diameter in the water are coarsely removed. When turning on the automatic operation switch of the system, at the beginning, the flocculant metering injection machine operates within a set time and a certain amount of flocculants are injected into the raw water stir tank. The stirring device in the tank continuously operates, at the time when the turbid water is put into the tank, the primary reaction begins. When the level meter in the raw water stir tank reaches the upper limit height, the flocculant metering injection machine starts up the operation at the same time when the turbid water is withdrawn by a pump and when the level meter reaches the lower limit position, water drawing by a pump is stopped. The flocculant metering injection machine operates within the set time after the squeeze pump stopped and a certain amount of flocculant is injected again to correspond to the raw water continuously pumped. By injection of the flocculant in advance before pumping the raw water, the raw turbid water was placed in contact with the flocculant at the time when the raw turbid water was put into the raw water stir tank. Inverter control of revolving speeds in each tank: at high speed in the raw water stir tank, at medium speed in the stir-reaction tank and at low speed in the raw water paddle in the vacuum hydrator respectively. The adoption of these processes made energy-saving and effective flocculating and settling reaction possible. As the solids which had been separated and discharged by the vacuum hydrator contained an asphalt ingredients and are fine-particles and high-viscosity, those are never discharged by use of screw and so on and directly put them into a bag or a container to prevent the flowing out and scattering of their chemicals. The solids packed in a bag or placed in a container are properly managed after measuring their weight and by clarifying their amount of emergence.

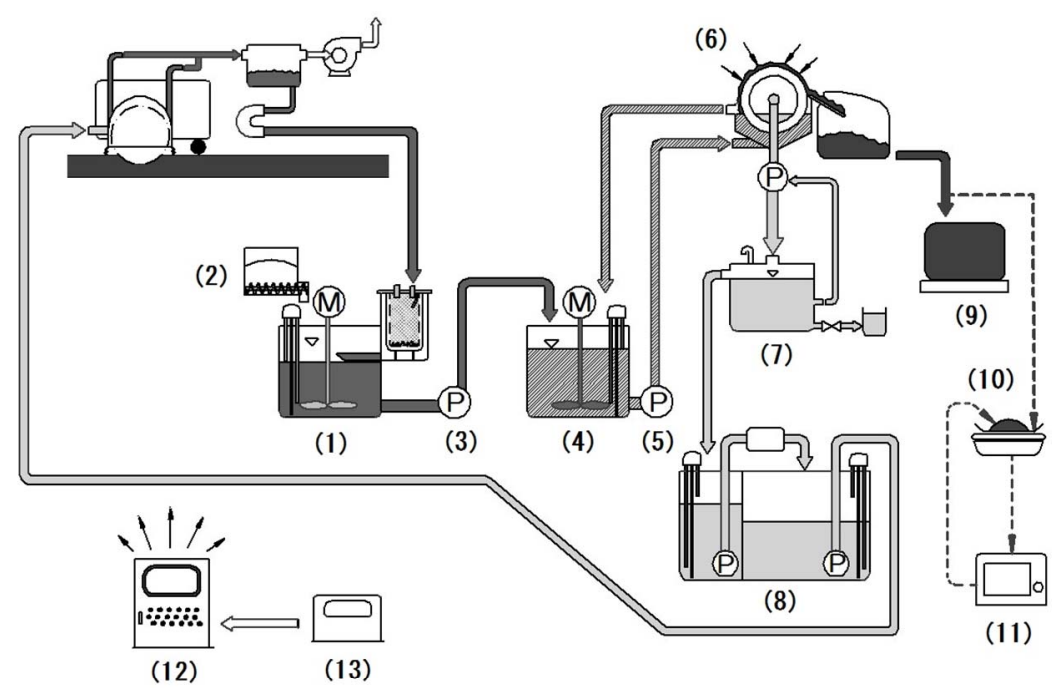

(1)Raw water stir tank, (2)Flocculant metering injection machine, (3)Pump, (4)Stir-reaction tank, (5)Pump, (6)Vacuum dehydrator (liquid-solid separator), (7)Feed water tank, (8)Filtrate tank, (9)Chenical drum, (10)Gravity meter, (11)Drier, (12)Control panel, (13)Power generator

Fig.1 Schematic diagram of mobile treatment unit for turbid water generated by cutting asphalt pavement surface 
On April $6^{\text {th }}, 2006$, the turbid water generated by cutting asphalt pavement surface had been taken from the repair worksite of asphalt pavement road and purified by using the developed treatment unit for turbid water. The raw turbid water and the purified water were measured on the basis of the certification of the drainage standard, the public notice No. 64 of the Ministry of the Environment, provided by the Minister of the Environment with the provision specifying the drainage standard of the ordinance of competent authority; the method of measurement: JISK0102-21 (glass electrode method) for the pH, the Appendix Table 8 of the public notice No. 59 of the Ministry of the Environment for the suspended solids (SS), the Appendix Table 4 of the public notice No. 64 of the Ministry of the Environment for the mineral oils and, on the normal-hexane extracts, JISK0102-17 for biochemical oxygen demand (BOD) and JISK0102-21 for chemical oxygen demand (COD). The $\mathrm{pH}$, the normal-hexane extracts, the SS, the BOD and the COD of the filtrate water and the $\mathrm{pH}$, the normal-hexane extracts and the water content ratio of the residues after processing of liquid-solid settling by the treatment unit were measured and these results are shown in Table 1. Further, the seven different kinds of polycyclic aromatic hydrocarbon (PAH), which is famous for its teratogenicity and carcinogenicity, were measured by a gas chromatography mass spectrometry for the turbid water generated by cutting asphalt pavement surface taken from the work site on June $4^{\text {th }}, 2007$. The measurement results of the purified water are shown in Table 2.

When turbid water generated by cutting asphalt pavement surface was treated by filtration after separating the liquid and solid by use of the developed treatment unit, it was found that the PAH (polycyclic aromatic hydrocarbon) of a carcinogenic chemical substance migrates into the residual solid and it was not contained in the filtrate water. In addition, it was found that the $\mathrm{pH}$, normal-hexane extracts, suspended solids, BOD and COD in the filtrate water are able to meet with the drainage standard.

Table 1 Measurement results of the raw turbid water and the purified water (I)

\begin{tabular}{|l|c|c|c|c|}
\hline \multicolumn{1}{|c|}{ Measurement items } & Turbid water & Filtrate water & $\begin{array}{c}\text { Drainage } \\
\text { standard }\end{array}$ & Residues \\
\hline Hydrogen-ion concentration & 9.1 at $22.5^{\circ} \mathrm{C}$ & 7.6 at $21.2^{\circ} \mathrm{C}$ & $5.8-8.6$ & 7.9 at $22.9^{\circ} \mathrm{C}$ \\
\hline Normal-hexane extracts & $3100 \mathrm{mg} / \ell$ & $<2.5 \mathrm{mg} / \ell$ & $200 \mathrm{mg} / \ell$ & $27800 \mathrm{mg} / \mathrm{kg}$ \\
\hline Suspended solids(SS) & $220000 \mathrm{mg} / \ell$ & $<10 \mathrm{mg} / \ell$ & $5 \mathrm{mg} / \ell$ & - \\
\hline $\begin{array}{l}\text { Biochemical oxygen demand } \\
\text { (BOD) }\end{array}$ & $37.5 \mathrm{mg} / \ell$ & $15.3 \mathrm{mg} / \ell$ & $160 \mathrm{mg} / \ell$ & - \\
\hline $\begin{array}{l}\text { Chemical oxygen demand } \\
\text { (COD) }\end{array}$ & $799 \mathrm{mg} / \ell$ & $10.7 \mathrm{mg} / \ell$ & $160 \mathrm{mg} / \ell$ & - \\
\hline Water content ratio & - & - & - & $26.7 \%$ \\
\hline
\end{tabular}

Table 2 Measurement results of the raw turbid water and the purified water (II)

\begin{tabular}{|l|c|c|}
\hline Measurement items & Turbid water & Residues \\
\hline Benzo[a]pyrene & $5700 \mathrm{ng} / \ell$ & $13,000 \mathrm{ng} / \mathrm{kg}$ \\
\hline Benz[a]anthracene & $2400 \mathrm{ng} / \ell$ & $6,200 \mathrm{ng} / \mathrm{kg}$ \\
\hline Chrysene & $9100 \mathrm{ng} / \ell$ & $16,000 \mathrm{ng} / \mathrm{kg}$ \\
\hline Benz[b+j]fluoranthene & $9400 \mathrm{ng} / \ell$ & $22,000 \mathrm{ng} / \mathrm{kg}$ \\
\hline Benz[k]fluoranthene & $2400 \mathrm{ng} / \ell$ & $※$ \\
\hline Indeno[1,2,3-cd]pyrene & $6800 \mathrm{ng} / \ell$ & $18,000 \mathrm{ng} / \mathrm{kg}$ \\
\hline Dibenz[a,h]anthracene & $※$ & $※$ \\
\hline
\end{tabular}

$※$ : Below the detection limit value 


\section{Demonstration test with the use of non- radioactive cesium}

In this demonstration test, the sea water which was pumped directly from Port Misaki and filtered with the filter of $1 \mu \mathrm{m}$ mesh was used. Such sea water was injected into the turbulent stir tank that has $50 \ell$ capacity and the simulated contaminated materials $(10 \mathrm{ppm}$ equivalent of the nuclides $\mathrm{Cs}$ and I were contained. There exists $8 \mathrm{ppm}$ of $\mathrm{Sr}$ in the sea water.) were added and stirred them until the whole becomes homogeneous, and then the iron ferrocyanide (Prussian blue) of $250 \mathrm{~g}$ was contained and the whole was turbulently stirred for about 5 minutes. The blue aqueous solution mixed with the simulated contaminated water and the iron ferrocyanide was pumped up to the treatment unit for turbid water generated by cutting asphalt pavement surface as shown in the Fig.1. Next, 50g of the flocculant was injected to the solution in two times and turbulently stirred in each time. After a while, the blue flocks were formed in the aqueous solution. Then they were flocculating and settling therein as clear liquid and solid sediments. Such a mixture was separated by a vacuum solids-liquid separator into the residues and filtrate water and the residues were continuously discharged. The decontamination efficiency achieved in this demonstration test was $99.5 \%$.

Since this demonstration test was held as an open experiment, the time for stirring after the injection of the iron ferrocyanide was limited and about 5 minutes. Considering the result of basic experiment, if the time for stirring extended to 10 minutes or so, it is expected to improve the decontamination efficiency.

\section{Conditions of cesium in paddles of water at the time when nine months have passed since the NPP accidents}

For the "Decontamination Technology Demonstration Test Activity" in FY2011 conducted by Japan Atomic Energy Agency as a part of the project "Demonstration Activity of Decontamination in the Evacuation Zones etc. induced by Fukushima Dai-ichi NPP Accident" commissioned by the Cabinet Office, the stationary purification system of contaminated water was manufactured by partially remodeling the stationary treatment system developed for the contaminated water generated by cutting asphalt pavement surface. The demonstration test was conducted by applying this purification system in an elementary school located at Motomiya City, Fukushima Prefecture.

The flow chart of this system is shown in Fig.2. The contaminated pool water is raised up with a pump to the inclined wedge wire screen and the mixtures with the size bigger than $0.4 \mathrm{~mm}$ in diameter are removed there, and then injected into the raw water stir tank. The raw water tank is equipped with a water level indicator, and when starting the injection of raw water into the tank, then start the stirring at the same time to prevent the settling of the suspended solids and when the raw water tank controlling equipment gets the signal of water level and if the signal that the water level reached at the certain level is received, the water is sent to the first stir-reaction tank. As the raw water feeding pumps are designed to make the injection of raw water into the two sets of stir-reaction tanks with the use of electrically-operated valves, etc. by the operation of either two units, and then these pumps are able to make continuous operation. In the first stir-reaction tank, when the water level becomes high, the flocculants of $0.1 \%$ by weight (to be adjusted according to the properties of contaminated water) is injected by use of the flocculant metering injection machine and the water is continuously stirred for 5 minutes or so, then the water is pumped to the second stir-reaction tank. In the second stir- reaction tank, similarly the flocculants of $0.1 \%$ by weight is injected by use of the flocculant metering injection machine and the water is continuously stirred for 5 minutes or so. It was found out that the two stages can reduce the input of flocculants and stirring time less than the single stage during the development. The 
treated water in the second stir-reaction tank flows to the thickener with the pump which is able to make fluid migration without spoiling the aggregates. The treated water in this thickener is separated to the solid-liquid because of the difference in specific gravities between the water and aggregates. The clear supernatant water shall be impound first in the filtrate tank, then flow to the tank with bag filter of $10 \mu \mathrm{m}$ by the pump which is able to make fluid migration and the water with suspended solids is filtered there. The aggregates settled at the bottom part in the thickener, as concentrated and contaminated mud with the water content around $80 \%$, are pumped to the solid-liquid separator, so called the Oliver-type vacuum dehydrator by the pump which can make fluid migration without spoiling the aggregates. After settling the solid-liquid by the separator, it would be solidified in the following two types of solids: In the case of containing a lot of organic bodies like algae, it would be the solid with water content around $50 \%$, and in the case of the inorganic fraction like a silt, it would be the solid with water content of around $30 \%$. Since this dehydration sludge is radioactive, it would be contained and stored in the stainless steel drum for chemicals after putting it into the excellent impermeable bag and so on while measuring its radioactivity by a dosimeter. The water filtrated by the vacuum dehydrator is pumped to the feed water tank to use as priming water and after that the water would be sent by its overflow to the filtrate tank and flow to the tank with bag filter by the pump which can make fluid migration. The purified water had been impound in tanks of $12 \mathrm{~m}^{3}$ and was released after inspecting that it satisfied the drainage standard. The board is the control panel controlling the whole system.

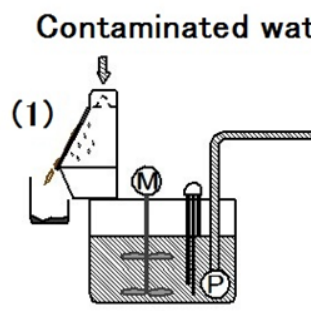

(2)

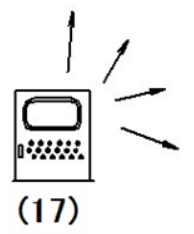

(4)

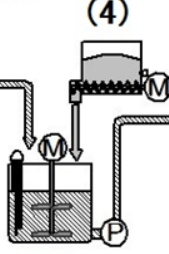

(3)
(6)

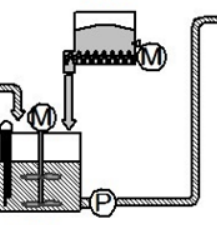

(5)

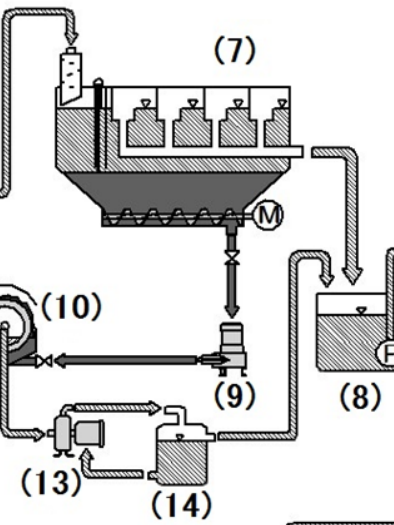

(14)

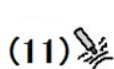

(12)

Drainage or clean water feed after dosimetry

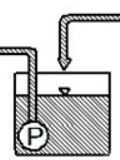

(16)

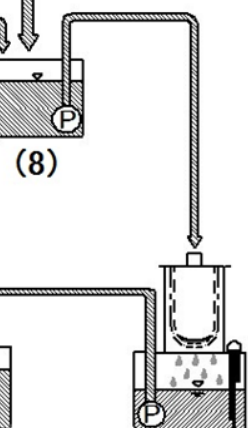

(15)

(1)Inclined wedge wire screen, (2)Raw water stir tank, (3)The first stir-reaction tank, (4)Flocculant metering injection machine, (5)The second stir-reaction tank,

(6)Flocculant metering injection machine, (7)Thickener, (8)Filtrate tank,

(9)Sludge pump, (10)Vacuum dehydrator, (11)Dosimeter, (12)Chemical drum,

(13)Vacuum pump, (14)Feed water tank, (15)Tank with bag filter, (16)Filtrate tank, (17)Control panel

Fig. 2 Stationary purification system of contaminated water

In the preliminary tests, two types of flocculants suitable to decontamination of contaminated pool water, namely the flocculant compounding iron ferrocyanide of $20 \%$ in 
ratio by weight (Ion reaction NF) and the non-compound flocculants (Ion reaction $\mathrm{N}$ ), were developed, and the purification of the pool water $(34-1,116 \mathrm{~Bq} / \ell$ in radiation dose) of about $300 \mathrm{~m}^{3}$ at the elementary school was conducted. In the results in each flocculant, the radiation dose of the purified pool water became lower than the detection limit value (about $10 \mathrm{~Bq} / \ell$ ) and the visibility of clean up water became more than $1 \mathrm{~m}$. These results clearly indicate that the pool water that is paddles of water at the time when nine months have passed since the NPP accidents contained less ionized Cs, that is, the radioactive Cs was absorbed into the body of algae such as green-blue algae and so on or adhering to finely divided soils suspended in the lower part of the pool.

5. Problems and development of countermeasure techniques when iron ferrocyanide is used for adsorbent of radioactive cesium

When iron ferrocyanide is used as the adsorbent of the ionized Cs, one of the pending problems is the liberation of cyanogen. From the result of the preliminary test by use of a beaker, it was found that the cyanide cannot be exceeded the drainable standard of $0.5 \mathrm{mg} / \ell$ when the iron ferrocyanide compounding ratio is less than $20 \%$. The demonstration test was, therefore, carried out by use of the flocculant compounding the iron ferrocyanide of $20 \%$ in ratio by weight. The results are shown in Table 3 . In the case where the iron ferrocyanide compounding ratio was $20 \%$, the cyanide concentration has not exceeded the drainable standard of $0.5 \mathrm{mg} / \ell$ as shown in the same table. Its highest concentration has, however, reached $0.44 \mathrm{mg} / \ell$, so that it is difficult to increase the compounding ratio of iron ferrocyanide more than $20 \%$. In the case where the $\mathrm{pH}$ of the contaminated water is high, it is necessary to measure the concentration of cyanide in the clarified water before its discharge.

Table 3 Measurement results of cyanide in clarified water

\begin{tabular}{|l|c|c|c|}
\hline & Date of sampling & $\begin{array}{c}\text { amount of cyanide } \\
\text { dissolution }\end{array}$ & Detection limit value \\
\hline Clarified water & 2011.12 .9 & $0.28 \mathrm{mg} / \ell$ & $0.02 \mathrm{mg} / \ell$ \\
\hline Clarified water & 2011.12 .9 & $0.33 \mathrm{mg} / \ell$ & $0.02 \mathrm{mg} / \ell$ \\
\hline Clarified water & 2011.12 .13 & $0.44 \mathrm{mg} / \ell$ & $0.02 \mathrm{mg} / \ell$ \\
\hline
\end{tabular}

As the ionized $\mathrm{Cs}$ in the environmental water is extremely small amount, the iron ferrocyanide compounding ratio $20 \%$ is excessive. Such a problem can be resolved by conducting a simple Cs removal test with the use of the contaminated water to be decontaminated and a proper compounding ratio can be found.

The sediments flocculated by the treatment of contaminated water are extracted from the bottom part of the thickener and become the dehydration sludge. In the case where the radiation dose of dehydration sludge is below the level of $8,000 \mathrm{~Bq} / \mathrm{kg}$, it would be possible to do landfill at the final disposal site. From the result of this demonstration test, even if the radiation dose of contaminated water was low level of $34-1,116 \mathrm{~Bq} / \ell$, its dehydration sludge, which has been concentrated and generated, became the radiation dose of 29,100 $77,200 \mathrm{~Bq} / \mathrm{kg}$ and it would be unable to do landfill.

In addition, the result of dissolution tests of cyanide which is based on the waste elution test of the Environment Agency's announcement No.13 in FY 1977 was as shown in Table 4. According to the table, where $20 \%$ of the iron ferrocyanide was contained, the amount of elution of cyanide would be $67 \mathrm{mg} / \ell$ and exceed the elution standard of $1 \mathrm{mg} / \ell$ substantially and then become specially-controlled waste. Therefore, the additional tests on the Ion reaction NF were conducted by the use of pool water. The compounding rates of iron ferrocyanide were $0.2 \%$ and $0.01 \%$ respectively and examined the rates of dissolution of 
cyanide in the dehydration sludge. The results are also as shown in the Table 4. Even with reducing the compounding rate to $0.01 \%$, the rate of dissolution of cyanide becomes $1.4 \mathrm{mg} / \ell$ and exceeds the elution standard. From these results mentioned above, it is necessary to use the Ion reaction NF for the decontamination of contaminated water where the ionized radioactive Cs does exist in the water. In such a case, it is necessary to establish the technology to eliminate the cyanide in the purified water and the technology to dissolve the cyanide in the dehydration sludge.

The measurements on the stability of the dehydration sludge had been attempted. Where the radioactive materials were re-eluted, methods of storage such as the total and complete water shielding should be explored. The analysis had been conducted to add the dehydration sludge of one tenth $(1 / 10)$ in ratio by weight to the distilled water and to vibrate them for six hours. After that, the suspected liquid was determined with the liquid obtained by filtration of the supernatant liquid with membrane filters of $0.45 \mu \mathrm{m}$. The suspected liquid had been measured by a germanium semiconductor detector for 2000 seconds. A marinelli beaker was used as the measuring vessel. In the result, the re-elution of cesium was not observed as shown in Table 5. The long term changes in the characteristics of the dehydration sludge have never been clear yet, but it was found that the short term stability was secured. From this, there are not any problems with storing of the dehydration sludge into impermeable bags and chemical drums in the meantime.

Table 4 Results of dissolution test of cyanogens compound from dehydration sludge

\begin{tabular}{|l|c|c|}
\hline \multicolumn{1}{|c|}{ Blend ratio of iron ferrocyanide } & $\begin{array}{c}\text { Amount of cyanide } \\
\text { dissolution }\end{array}$ & $\begin{array}{c}\text { Detection limit } \\
\text { value }\end{array}$ \\
\hline Dehydration sludge (Iron ferrocyanide $20 \%$ ) & $67 \mathrm{mg} / \ell$ & $0.1 \mathrm{mg} / \ell$ \\
\hline Dehydration sludge (Iron ferrocyanide $0.2 \%$ ) & $5.2 \mathrm{mg} / \ell$ & $0.1 \mathrm{mg} / \ell$ \\
\hline Dehydration sludge (Iron ferrocyanide $0.01 \%$ ) & $1.4 \mathrm{mg} / \ell$ & $0.1 \mathrm{mg} / \ell$ \\
\hline
\end{tabular}

$※$ Dissolution standard : $1.0 \mathrm{mg} / \ell$

Table 5 Results of dissolution test of dehydrate sludge

\begin{tabular}{|l|c|c|c|}
\hline & ${ }^{131} \mathrm{I}$ & ${ }^{134} \mathrm{Cs}$ & ${ }^{137} \mathrm{Cs}$ \\
\hline Dehydrate sludge & ND $(1.06 \mathrm{~Bq} / \ell)$ & ND $(1.84 \mathrm{~Bq} / \ell)$ & ND $(1.40 \mathrm{~Bq} / \ell)$ \\
\hline
\end{tabular}

$※$ Number shown in parentheses ( ): The detection limit value

ND means non detection.

6. High-performance mobile purification systems of contaminated water and their decontamination demonstration tests of contaminated water

\subsection{Newly developed high-performance mobile purification units of contaminated water}

The mobile purification unit for turbid water generated in cutting asphalt pavement surface was not high and around $170 \mathrm{\ell} / \mathrm{h}$ in treatment performance because the unit performs the vacuum-dehydration for the total volume of contaminated water without using a thickener. To improve the treatment performance, a thickener, two sets of the first stir-reaction tank and two filtrate tanks with bag filter were installed, and the modification of mobile purification unit of contaminated water was considered, which becomes able to make continuous operation by a relay system, taking into account of the demonstration test results ${ }^{(4)}$ of the stationary purification system of contaminated water. The new mobile purification unit for exclusive use of radioactively contaminated water was designed on the basis of the abovementioned modifications and manufactured. The unit that is the size capable of carrying with a $4 \mathrm{t}$ truck is shown in Fig.3. Its performance efficiency is around 
$2 \mathrm{~m}^{3} / \mathrm{h}$. In conjunction with this unit, the other which is the processing capacity of $600 \ell / \mathrm{h}$ and capable of carrying with a $2 \mathrm{t}$ truck was manufactured.

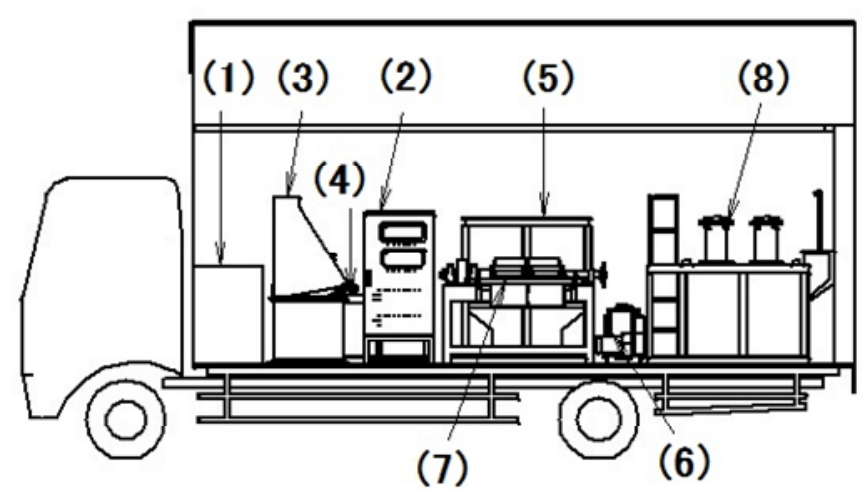

(1)Power supply, (2)Control panel, (3)Inclined wedge wire screen, (4)First and second stir-reaction tank, (5)Thickener,

(6)Flocculant metering injection machine, (7)Vacuum dehydrator,

(8)Filtrate tank with filter fabric

Fig.3 Mobile purification unit for contaminated water

\subsection{Demonstration tests for the decontamination}

At the request of the Minami-soma cooperative for the decontamination of contaminated water, the decontamination demonstration tests for the contaminated water were conducted as follows: The demonstration test for the decontaminated water generated by the high-pressure water washing in the Takakura Public Hall was conducted by the mobile purification unit that is capable of carrying with a $4 \mathrm{t}$ truck. The other test for the contaminated water in a pond in Heartland was carried out by the mobile purification unit that is capable of carrying with a $2 t$ truck due to the narrow road width near pond.

The measurements of radiation doses and the isotopic analyses of Cs were carried out by the use of a germanium semiconductor detector and a $2 \ell$ marinelli beaker with the measuring time of 2500 seconds. The mobile purification unit of contaminated water was installed on the side of pond and the water pumped up from the pond by a submersible pump was sent to the unit. The treated water was stored in a notch tank. The flocculant (Ion reaction $\mathrm{N}$ ) without iron ferrocyanide was used and its additive amount was set as $0.1 \%$. The measuring results of the raw water and treated water are shown in Table 6 in the case where the mobile purification units were used to process the contaminated water. It is clarified from the table that the both measuring results of ${ }^{134} \mathrm{Cs}$ and ${ }^{137} \mathrm{Cs}$ were below the detection limit value.

Table 6 Radiation doses of the contaminated water of pond and the building decontamination water

\begin{tabular}{|l|c|c|c|}
\hline & ${ }^{134} \mathrm{Cs}$ & ${ }^{137} \mathrm{Cs}$ & Total \\
\hline Pond: raw water & $89.5 \mathrm{~Bq} / \ell$ & $135 \mathrm{~Bq} / \ell$ & $224.5 \mathrm{~Bq} / \ell$ \\
\hline Pond: treated water & $\mathrm{ND}(0.655 \mathrm{~Bq} / \ell)$ & $\mathrm{ND}(0.594 \mathrm{~Bq} / \ell)$ & $\mathrm{ND}$ \\
\hline Building decontamination raw water & $429 \mathrm{~Bq} / \ell$ & $638 \mathrm{~Bq} / \ell$ & $1,067 \mathrm{~Bq} / \ell$ \\
\hline Building decontamination treated water & $6.46 \mathrm{~Bq} / \ell$ & $8.93 \mathrm{~Bq} / \ell$ & $15.39 \mathrm{~Bq} / \ell$ \\
\hline
\end{tabular}


A portion of the Takakura Public Hall was washed by the use of the high-pressure water jet apparatus. The radiation doses of the contaminated washing water and its treated one were measured, and their results are shown in Table 6 . The radiation dose of Cs in the water contaminated by washing became $1,067 \mathrm{~Bq} / \ell$ and it is therefore necessary to decontaminate the water generated by washing contaminated buildings. As for the contaminated water of the pond, the radiation dose of $\mathrm{Cs}$ for treated water could be reduced below the detection limit value. However, the radiation dose for treated one was higher than the detection limit value, namely $15.39 \mathrm{~Bq} / \ell$ as shown in Table 6 . In this case, a half of the additive amount of flocculant, which was $0.05 \%$, was added in comparison with the treatment of contaminated pond water. It was thought to be due to the insufficient of the additive amount of the flocculant. The additional test was carried out, where the amount of flocculant of $0.1 \%$ was added in contaminated washing water. In this case, the radiation dose of Cs for treated water could be lower than the detection limit value.

After the decontamination treatment of the contaminated water in the pond and generated by washing the building, the radiation doses of the dehydration sludge generated by the treatment were measured. These measurement results were summarized in Table 7 . The radiation doses became high concentration such as $3,430 \mathrm{~Bq} / \ell$ for the dehydration sludge after liquid-solid settling of the contaminated water of the pond and $184,600 \mathrm{~Bq} / \mathrm{kg}$ for the washing water of the building respectively.

Table 7 Dehydration sludge

\begin{tabular}{|l|c|c|c|}
\hline & ${ }^{134} \mathrm{Cs}$ & ${ }^{137} \mathrm{Cs}$ & Total \\
\hline Pond: dehydration sludge & $1,390 \mathrm{~Bq} / \mathrm{kg}$ & $2,040 \mathrm{~Bq} / \mathrm{kg}$ & $3,430 \mathrm{~Bq} / \mathrm{kg}$ \\
\hline Building: dehydration sludge & $73,600 \mathrm{~Bq} / \mathrm{kg}$ & $111,000 \mathrm{~Bq} / \mathrm{kg}$ & $184,600 \mathrm{~Bq} / \mathrm{kg}$ \\
\hline
\end{tabular}

\section{Conclusions}

The authors' group were being developed the inorganic flocculants "Ion reaction" removable of suspended solids including oil components in water and capable of $\mathrm{pH}$ control and highly-efficient flocculating and settling technology based on the turbulence stirring technology before March $11^{\text {th }}$, 2011. As a part of the activities to curb the effects with Fukushima Dai-ichi NPP accidents and to treat the radioactive contamination outside the NPPs, the chemical study group of the Research Laboratory for Nuclear Reactors, Tokyo Institute of Technology initiated its research and development of decontamination technology for contaminated water and found that iron ferrocyanide could be applied to the adsorption of ionized $\mathrm{Cs}$ and finally established the decontamination technology to remove ionized Cs from the contaminated water. The authors' group developed the flocculant 'Ion reaction NF" compounding the iron ferrocyanide and the non-compounding flocculants "Ion reaction N", and further developed and improved a purification system of contaminated water generated in cutting asphalt pavement surface into the stationary purification system of contaminated water and the mobile purification unit of contaminated water. The demonstration tests of the decontamination of contaminated water of the pools were actually conducted at an elementary school located at Motomiya City, Fukushima Prefecture using the abovementioned technologies and systems. The followings have been made clear from the results of the demonstration tests:

(1) At the time when nine months have passed since the NPP accidents, paddles of water in the pool contained less ionized Cs: the radioactive Cs was absorbed into the body of algae such as green-blue algae and so on or adhering to finely-divided soils suspended in the lower part of the pool. 
(2) The contaminated pool water was able to be decontaminated below the detection limit value. During this demonstration test, the mobile purification units of contaminated water was designed and manufactured which are capable of carrying with a 4 t truck (contaminated water processing capacity: $2 \mathrm{~m}^{2} / \mathrm{h}$ ) and capable of carrying with a $2 \mathrm{t}$ truck (processing capacity: $600 \mathrm{\ell} / \mathrm{h}$ ), for the purpose of purification of the contaminated water generated from washing residential buildings, roads, rubbles and so on as requested by the local community.

The demonstration tests for the contaminated water resulting from the decontamination in the Takakura Public Hall and the contaminated paddles of water in the pond in the Heartland at Minami-Soma City were conducted by using our developed mobile purification units, and the followings were clarified:

(3) The radiation doses of the paddles of water in the pond and the contaminated water generated from washing the building were not as high as at levels ranging from 225 to $1,067 \mathrm{~Bq} / \ell$. When $0.1 \%$ by weight of the flocculant which contain none of iron ferrocyanide was added to the contaminated water to separate the liquid-solid, then the radiation doses of clarified water can be lowered than the detection limit value $(1.25 \mathrm{~Bq} / \ell)$ by decontamination.

(4) As for the dehydration sludge that has been separated by liquid-solid settling of the contaminated water which has been generated from the decontamination of residential buildings by water washing, it was found to be the high radiation dose as $184,600 \mathrm{~Bq} / \mathrm{kg}$. For this reason, it is necessary to place them in to a container provided with radiation shielding function in order to store them temporarily on the empty lot and so on until the construction of interim storage facilities are completed.

\section{References}

(1) J. Takanashi, S. Hosobuchi and M. Aritomi, Study on water treatment system for cutting asphalt road (1st Report, Development of water treatment system for cutting asphalt road), Trans. JSME, Series B, Vol.75, No.760, (2009) pp.2504-2510. (in Japanese)

(2) J.Benes and M.Kyrs, The isolation of Caesium-137 from liquid radioactive fall-out, Anal. Chim, Acia, Vol.29 (1963) pp.564-568.

(3) K. Takeshita and T. Ogata, Application of ion exchange technique to decontamination of polluted water generated by Fukushima nuclear disaster, J. Ion Exchange, Vol.23 (2012) pp.1-5. (in Japanese)

(4) M. Aritomi, Report: Study on decontamination system of contaminated water using flocculants compounding iron ferrocyanide, "Decontamination Technology Demonstration Test Activity” in FY 2011 conducted by JAEA , (2012.2). (in Japanese) 